\title{
太湖贡湖湾人工湖滨带水生植物恢复及其富营养化控制”
}

\author{
姚 程 $^{1,2}$, 胡小贞 ${ }^{2}$, 姜 霞 $^{2}$, 陈俊伊 ${ }^{2}$, 王 坤 $^{1,2 * *}$ \\ (1: 北京师范大学水科学研究院, 北京 100875$)$ \\ (2: 中国环境科学研究院湖泊水污染治理与生态修复国家工程实验室,北京 100012)
}

\begin{abstract}
摘 要: 以太湖贡湖湾人工湖滨带为对象, 研究湖滨水生植物修复过程及其富营养化控制效果. 人工湖滨区域内的消浪 带、岸上护坡措施为水生植物修复提供了良好的生境条件,形成了包括荇菜 (Nymphoides peltatum (Gmel.) Kuntze)、睡莲 ( Nymphaea tetragona Georgi)、菱 (Trapa bispinosa Roxb.) 为主的浮叶植物群落, 以及以黑藻 (Hydrilla verticillata (Linn. f.) Royle)、狐尾藻 (Myriophyllum verticillatum L.) 、小眼子菜 (Potamogeton pusillus L.)、竹叶眼子菜 (Potamogeton malaianus) 为 主的沉水植物群落. 通过设置研究区、对照区, 持续监测溶解氧、总氮、总磷、氨氮、叶绿素 $a$ 浓度等水体指标, 烧失量、氮 含量、磷含量等沉积物指标, 水生植物生物量、覆盖度, 浮游藻类等指标. 不同时期、不同区域间的时空分布显示: 随着水 生植物的恢复, 水体营养状态指数 $(T L I)$ 、沉积物生物生产力指数 $(B P I)$ 显著下降, 水体透明度显著提升; 较高浓度的总氮 $(>3.0 \mathrm{mg} / \mathrm{L})$ 、氨氮 $(>0.6 \mathrm{mg} / \mathrm{L})$ 环境不利于浮叶植物的生长, 沉水植物对其则表现出更好的适应性, 同时水生植物在成 长过程中直接从水体/沉积物中吸收氮; 颤藻 (Cyanophyta oscillatoria) 、直裂藻 (Cyanophyta merismopedia) 等浮游藻类吸收 了水体磷, 水生植物利用了沉积物磷, 共同缓解了磷在湖滨区域的累计. 总结以上, 湖滨带的水文水质条件可以影响水生 植物群落结构, 进而决定氮、磷的控制效果, 所以在湖滨带修复中构建合适的生境条件是水生植物发挥氮磷控制效果的 重要前提. 水生植物在恢复过程中对浮游藻类群落结构的影响是显著的,并且以此影响到湖滨水体中磷的分布.
\end{abstract}

关键词: 太湖;贡湖湾;湖滨带;水生植物;富营养化;浮游藻类;沉积物

\section{Macrophytes restoration and its effects on eutrophication control in rehabilitated lakeshore zone of Gonghu Bay, Lake Taihu*}

Yao Cheng ${ }^{1,2}$, Hu Xiaozhen ${ }^{2}$, Jiang Xia ${ }^{2}$, Chen Junyi ${ }^{2}$ \& Wang Kun ${ }^{1,2 * *}$

(1: College of Water Science, Beijing Normal University, Beijing 100875, P.R. China)

(2: National Engineering Laboratory for Lake Pollution Control and Ecological Restoration, Chinese Research Academy of Environmental Sciences, Beijing 100012, P.R.China)

Abstract: A rehabilitated lakeshore zone in Gonghu Bay, Lake Taihu, China was chosen to study macrophytes restoration and its
effects on eutrophication control. The facilities including wave-weakening belts and bank revetment in rehabilitated lakeshore pro-
vided habitat for floating-leaved macrophytes, like Nymphoides peltatum (Gmel.) Kuntze, Nymphaea tetragona Georgi, Trapa
bispinosa Roxb., etc. and submerged macrophytes, like Hydrilla verticillate, Myriophyllum verticillatum L., Potamogeton pusillus
L., Potamogeton malaianus, etc.. The continuously monitoring on dissolved oxygen, total nitrogen, total phosphorus, ammonia,
chlorophyll-a concentrations of water, ignition loss, nitrogen, phosphorus contents of sediment, macrophytes' coverages and bio-
mass, phytoplankton's density were performed between two study areas and reference area. The space-time distribution of different
areas and stages indicated that the trophic level index ( TLI) of water and the bioproduction index (BPI) of sediment were remark-
edly reduced, the water transparency was significantly increased as the macrophytes restored. The relatively high levels of total ni-
trogen ( $>3.0 \mathrm{mg} / \mathrm{L}$ ) and ammonia ( >0.6 mg/L) were the condition unfavorable for the floating-leaved macrophytes but not for the
submerged macrophytes, in the meanwhile nitrogen of water and sediment were utilized directly during the macrophytes' restoration.
Phytoplankton like Cyanophyta oscillatoria, Cyanophyta merismopedia and etc. absorbing phosphorus from water directly and mac-

* 2020-10-22 收稿; 2021-03-24 收修改稿.

国家水体污染控制与治理科技重大专项 (2017ZX07206) 资助.

** 通信作者; E-mail: wangkun@ craes.org.cn. 
rophytes utilizing phosphorus in sediment collaboratively alleviated the phosphorus accumulation in lakeshore. Overall, it is concluded that the hydrological condition and water quality have impact on structure of macrophyte communities in the restoration, thus affecting the efficiency of nitrogen and phosphorus control. The macrophytes restoration had significant influences on planktonic communities, of which were directly correlated with phosphorus distribution in lakeshore water.

Keywords: Lake Taihu; Gonghu Bay; lakeshore; macrophytes; eutrophication; phytoplankton; sediment

湖滨带是湖泊、陆地生态系统之间的重要过渡区,具有拦截污染物、防止土壤侵蚀、提供栖息地等生态 功能 ${ }^{[1]}$. 由于污废排放、土地开发, 湖滨生态系统正逐渐被破坏、侵蚀, 逐渐失去了以上生态功能, 加剧了湖 泊富营养化等问题 ${ }^{[2]}$. 湖滨带修复正是在此背景下提出, 内容主要包括修复被破坏的湖滨景观,显著降低污 染物浓度, 恢复湖滨带生物多样性等 ${ }^{[3]}$. 重建水生植物群落是湖滨带修复过程中最常用的技术手段, 例如 加拿大锡姆科湖 (Lake Simcoe) 就采取重建沿岸水生植物群落的方式控制磷点源污染, 捷克利普诺水库 (Lipno Reservoir) 沿坝体重建水生植物群落, 恢复当地生物多样性, 美化水库沿岸 ${ }^{[4-5]}$. 我国近年来在太湖、 巢湖、鄱阳湖等地开展的湖滨带生态修复项目中也广泛实施了水生植物群落重建 ${ }^{[6-8]}$.

水生植物在控制湖泊富营化方面发挥着重要作用. 洪湖湖滨带长期监测结果显示完整的沉水、挺水、浮 叶植物群落提高了湖泊的自净能力, 缓解了湖泊富营化趋势 ${ }^{[9]}$. 在滇池、洱海湖滨带水生植物控制水体氮 磷, 抑制了藻类活动 ${ }^{[10]}$. 沉水植物群落还可以稳定基底, 减少水力扰动带来的沉积物再悬浮, 提高水体透明 度 ${ }^{[11]}$. 室内模拟试验结果显示水生植物不但可以适应高氮磷环境, 在生长过程中还能稳定同化氮磷元素, 全生命周期内减缓氮磷循环速度 ${ }^{[12-14]}$. 但是水生植物生长还受到水位以及自身习性的影响, 例如水体富营 养化压力下浮叶植物往往比沉水植物表现出更强的适应性 ${ }^{[15-16]}$. 水生植物群落重建过程中的适应性以及 氮、磷控制效果上的讨论仍在继续. 例如沉水植物生长一方面可以吸收水体中的可溶性磷, 同时也会提高沉 积物中磷的有效性, 增加湖泊中磷的内源释放风险 ${ }^{[17]}$. 尤其在退圩还湖、生态修复过程中人工构建湖滨带 水生植物的适应性以及对水体一沉积物系统中氮磷的控制效果还需要进一步观察研究.

贡湖湾位于我国太湖东北部, 是太湖的重要组成部分, 紧邻江苏省无锡市, 与贯穿市区的河网紧密相连. 1970s 因为城镇发展, 当地采取填湖筑坝的方式破坏了当地自然湖滨带, 沿岸水生植物群落基本消失, 伴随 着市政污水排放压力, 自 2000 年起频繁的蓝藻暴发成为影响当地用水安全的主要问题 ${ }^{[18]}$. 贡湖湾主体湖区 在 2008 年总氮浓度达到 $4.0 \mathrm{mg} / \mathrm{L}$ 以上, 总磷浓度达到 $0.05 \mathrm{mg} / \mathrm{L}$ 以上, 湖滨区域由于市政污水压力, 总氮、 总磷浓度更高 ${ }^{[19]} .2012$ 年起以恢复自然湖滨带、控制入湖氮磷浓度为目的的生态修复工程在贡湖湾湖滨带 实施, 重建水生植物群落是其中重要环节. 各类水生植物对人工基底、高氮磷水体的适应性, 以及缓解富营 化的效果有待研究.

流域尺度上的野外调查和微观层面上的室内模拟取得了丰富的各类成果, 但中/小尺度下水生植物的 恢复以及氮磷控制效果还需要补充完善. 人工修复湖滨区域为研究水生植物生长对水深、水质等环境因素 的适应性提供了良好条件, 而不同的水生植物群落构成是否影响其氮磷控制效果将得到进一步验证. 本研 究拟从水生植物移植栽种初期到基本稳定的成熟期, 以季度为时间单位, 为期 3 年, 现场监测水体、沉积物 氮磷含量, 浮游藻类及水生植物生长情况. 通过量化、分析水生植物生长情况以及与氮磷含量的相关关系, 以期系统地阐述水生植物的恢复过程以及在控制湖泊富营化上发挥的作用, 进一步丰富水生植物在湖泊保 护上的工程应用.

\section{1 研究区域与方法}

\section{1 研究区域}

湖滨带修复区位于太湖贡湖湾北部沿岸, 紧邻无锡市区. 如图 1 所示, 整个修复区四周由护堤包围, 修 复区与贡湖湾主体相连且东侧与无锡市区河网入湖口相连. 护堤内原属 $1970 \mathrm{~s}$ 围湖造田形成的农业用地, 2012 年以来完成了以基底重建为主的湖滨带修复初步工作. 整个湖滨带修复区在 2012 年完成了基底重建, 为 2014 年全面开展水生植物群落重建打下基础, 至 2016 年基本完成湖滨带水生植物重建. 为了研究不同水 生植物在修复期间的生长情况以及氮、磷控制效果, 在湖滨带修复区内选取 2 个研究区域、1 个参考对照区. 研究区 A $\left(31^{\circ} 27^{\prime} 19.91^{\prime \prime} \sim 31^{\circ} 27^{\prime} 25.38^{\prime \prime} \mathrm{N}, 120^{\circ} 19^{\prime} 48.04^{\prime \prime} \sim 120^{\circ} 19^{\prime} 56.39^{\prime \prime} \mathrm{E}\right)$ 位于湖滨带修复区北岸, 在 $150 \mathrm{~m} \times 180$ 
$m$ 的矩形区域内沿着水深变化栽种了浮叶、沉水植物并在南侧设置了消浪带. 研究区 B $\left(31^{\circ} 27^{\prime} 10.59^{\prime \prime} \sim\right.$ $31^{\circ} 27^{\prime} 12.71^{\prime \prime} \mathrm{N}, 120^{\circ} 20^{\prime} 4.91^{\prime \prime} \sim 120^{\circ} 20^{\prime} 6.30^{\prime \prime} \mathrm{E}$ ) 位于湖滨带修复区南侧, 在 $90 \mathrm{~m} \times 100 \mathrm{~m}$ 的矩形区域内设置 消浪带、栽种水生植物. 对照区位于修复区中心, 修复期间仅处理了基底、栽种少量沉水植物, 未设置消浪带 或栽种其他水生植物. 研究区、对照区在 2012 年基本完成基底构建, 在清除原农田土壤后覆盖当地沙壤土. 研究区 A 及对照区按照 3\%的设计坡度找坡,研究区 B 则按照 $5 \%$ 的设计坡度找坡,水深均按照最深处 $2 \mathrm{~m}$ 的设计构建基底. 2013 年完成岸上植物的栽种, 并种植市售水生植物幼苗. 根据岸坡坡度及设计水深, 从岸 边向底部栽种浮叶、沉水植物. 研究区内水生植物种类丰富, 且具备完善的消浪围护, 为研究水生植物的恢 复和作用提供了良好条件.

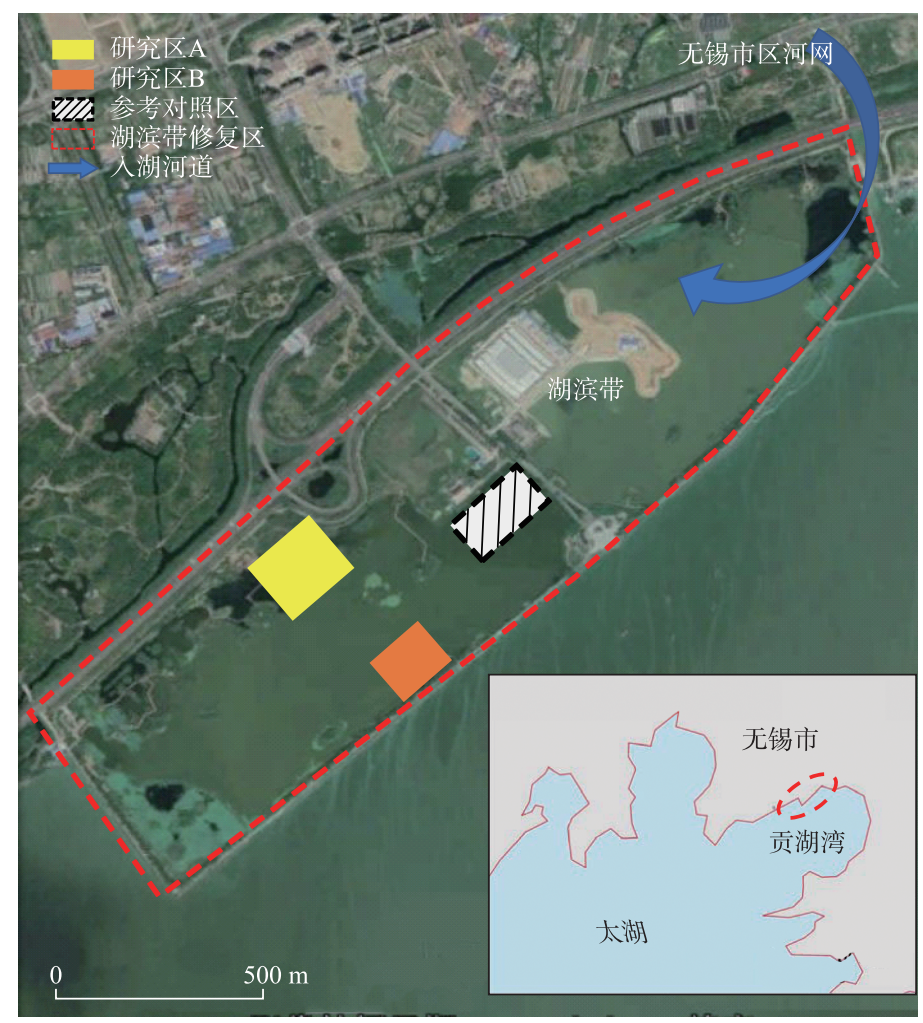

图 1 太湖贡湖湾湖滨带生态修复区以及研究区 A 、研究区 B、对照区

Fig.1 The study area (A, B) and control area in ecological restoration of Gonghu Bay, Lake Taihu

\section{2 研究方法}

2014-2016 年每年夏季 ( 6 月)、冬季 (12 月) 对研究区内的水体、沉积物和水生植物指标进行监测. 在 研究区 A、B 以及对照区内分别设置 6 个、 5 个采样点, 采集水体、沉积物样本. 水生植物统计根据样方法 ${ }^{[20]}$, 分别在两个研究区内设置 $20 \mathrm{~cm} \times 20 \mathrm{~cm}$ 样方 $33 、 28$ 个. 水体化学需氧量 $\left(\mathrm{COD}_{\mathrm{Mn}}\right)$ 、氨氮 $\left(\mathrm{NH}_{3}-\mathrm{N}\right)$ 、总氮 $(\mathrm{TN}) 、$ 总磷 (TP)、叶绿素 $a(\mathrm{Chl} . a)$ 浓度等指标在采样 $24 \mathrm{~h}$ 内带回实验室根据标准方法检测 ${ }^{[21]}$, 水体透明 度 $(\mathrm{SD})$ 在现场由透明度盘测定. 使用彼得逊采泥器采集表层沉积物 $(0 \sim 5 \mathrm{~cm})$ 样品, 沉积物样品采取冷冻干 燥方式前处理, 粉碎过篮 (孔径: $150 \mu \mathrm{m}$ ) 以去除动植物组织和岩石颗粒的干扰, 进一步过篎 (孔径: $75 \mu \mathrm{m}$ ) 备用. 沉积物有机物含量由烧失量 (ignition loss, IG) 表示, 称量单位沉积物样品质量在 $550^{\circ} \mathrm{C}$ 焚烧 $2 \mathrm{~h}$ 后变 化所测定. 沉积物磷含量由高氯酸、硫酸消解法所得. 沉积物氮含量根据凯式定氮法利用自动化蒸馏滴定系 统测定 (VELP Scientifica, Usmate, Italy). 浮游藻类的采集、固定、镜检分类计数采用《水和废水监测分析方 法》(第四版 $)^{[22]}$ 及水生生物分类鉴定图谱. 
湖泊营养状态指数 (trophic level index, TLI) 是评价湖泊营养化程度的综合性指标, 该指数将叶绿素 $a$ 、 总磷、总氮、透明度、化学需氧量作为主要参数, 并根据全球各地长期观察结果为基准建立起一套无量纲过 程和划分标准 ${ }^{[23]}$. 该指数在长江流域湖泊中的应用证明了其对我国湖泊富营养化情况的适应性 ${ }^{[24-25]}$. TLI 计算公式如下:

$$
\begin{gathered}
T L I(\text { Chl. } a)=10 \times(2.5+1.086 \ln (\text { Chl. } a)) \\
T L I(\mathrm{TP})=10 \times(9.436+1.642 \ln (\mathrm{TP})) \\
T L I(\mathrm{TN})=10 \times(5.453+1.694 \ln (\mathrm{TN})) \\
T L I(\mathrm{SD})=10 \times(5.118-1.94 \ln (\mathrm{SD})) \\
T L I\left(\mathrm{COD}_{\mathrm{Mn}}\right)=10 \times\left(0.109+2.66 \ln \left(\mathrm{COD}_{\mathrm{Mn}}\right)\right) \\
T L I(\Sigma)=\sum_{i}^{5} w_{i} \operatorname{TLI}(i)
\end{gathered}
$$

湖泊综合营养状态指数 $T L I(\Sigma)<30$, 水体呈贫营养; $30 \leqslant T L I(\Sigma)<50$, 水体呈中营养; $50 \leqslant T L I(\Sigma)<$ 70 , 水体呈富营养; $70 \leqslant T L I\left(\sum\right)$, 水体呈严重富营养.

生物生产力指数 (bio-production index, BPI) 是从沉积物角度评价湖泊营养程度的常用指标, 反映了一 个湖泊生态系统长期、整体上所能承载的生物量. 不同于水体 $T L I$ 主要针对浮游植物的营养程度评价, $B P I$ 是反映包括浮游动植物、水生植物、底栖动物在内整个生态系统所能获得的营养水平 ${ }^{[26]}$. 对于初期的人工 生态系统, $B P I$ 主要反映湖滨带对水生植物的支持能力, 同时也反映外源营养物质在湖滨带的积累情况. 根 据 BPI 的定义, 在沉积物氮含量与有机物含量的线性回归中 $\omega(\mathrm{IG})=100 \% 0$ 时所对应的氮含量. 这是一种建 立在碳氮比例和数量下对湖泊生态承载力的估算, $B P I$ 指数与湖泊水体富营养化间的相关关系在国内外研 究中得到了印证.

\section{3 数据分析}

为保证数据的准确性和可靠性, 所有样品分析过程中均采取平行检测, 标准物质采用 Sigma-Aldrich RTC 公司水系沉积物标准品 CNS392. 本研究重复样本分析误差 $<5 \%$, 标准物质测试误差 $< \pm 10 \%$. 本研究指 标间独立性采取样本独立 $t$ 检验. 利用 Pearson 分析法处理水体指标之间的相关关系. 水体氮、磷浓度与水 生植物生物量、覆盖度之间的线性回归以及沉积物有机物、氮含量之间的线性回归采用 SPSS 22 软件 (IBM, Armonk, NY, USA) 执行.

\section{2 结果分析}

\section{1 水生植物的恢复}

研究区内的主要浮叶植物有荇菜 (Nymphoides peltatum (Gmel.) Kuntze)、睡莲 (Nymphaea tetragona Georgi) 、菱( Trapa bispinosa Roxb.), 主要沉水植物包括黑藻 (Hydrilla verticillata (Linn. f.) Royle)、狐尾藻 (Myriophyllum verticillatum L.) 、小眼子菜 (Potamogeton pusillus L.)、竹叶眼子菜 (Potamogeton malaianus). 水生植物 恢复采取幼苗移植的方式, 浮叶植物种植密度为: 睡莲 $2 \sim 3$ 株 $/ \mathrm{m}^{2}$, 荇菜 $20 \sim 30$ 株 $/ \mathrm{m}^{2}$, 菱 $5 \sim 6$ 株 $/ \mathrm{m}^{2}$; 沉水 植物种植密度为: 竹叶眼子菜 $50 \sim 60$ 株 $/ \mathrm{m}^{2}$, 小眼子菜和黑藻均为 $40 \sim 45$ 株 $/ \mathrm{m}^{2}$, 狐尾藻 $30 \sim 40$ 株 $/ \mathrm{m}^{2}$. 如图 2 所示植物栽种后逐渐恢复水位, 在 2014 年水生植物群落初步成熟. 湖滨带水生植物恢复在一定程度上依 赖于消浪技术的应用, 良好的水体透明度是水生植物, 尤其是沉水植物生存的必要条件 ${ }^{[27-29]}$, 而低透明度甚 至可能带来沉水植物的消亡 ${ }^{[30]}$. 以人工构造围护、消浪带为代表的消浪技术在太湖五里湖区域的应用证明 了其在减少水力扰动、提高水体透明度方面的价值 ${ }^{[8]}$. 水生植物的生长促进了水体透明度的提高. 图 $3 \mathrm{a}$ 反 映出沉水植物生物量与水体透明度表现出良好的正相关 ( Pearson's $r>0.89, R^{2}>0.75$ ). 人工消浪措施为修复 初期水生植物的生长提供了良好的水力条件和水体透明度, 随着水生植物的生长水体透明度得到进一步提 高. 研究区 $\mathrm{A}$ 在 2014 年时水体透明度就好于研究区 $\mathrm{B}$, 并且伴随着水生植物的生长有着更快的提高. 图 $3 \mathrm{~b}$ 反映出浮叶植物的覆盖度与水体透明度之间的正相关关系 ( Pearson's $r=0.92, R^{2}=0.95$ ), 进一步说明水生 植物的恢复利于水体透明度的提高.

不同植物习性各异, 浮叶植物开花、持续时间也不尽相同. 例如, 菱作为一年生草本水生植物, 冬季时除 
沉积物中留存的母茎外, 枝杆枯黄, 叶子和果实枯死返回沉积物, 所以其生物量和覆盖度在冬季时可以忽略 不记. 如表 1 所示, 总体上植物覆盖度、生物量在夏季达到最高, 在冬季处于最低水平, 逐年稳定增长. 通过 对比研究区 A、B 内的水生植物, 可以发现研究区 $A$ 的浮叶植物覆盖度、生物量更高, 在研究区 $\mathrm{A}$ 内荇菜、菱 的分布更为广泛,而研究区 $B$ 内睡莲分布则较广. 研究区 $A 、 B$ 基底坡度的不同可能是造成这种差异的原因 之一. 研究区 $\mathrm{A}$ 内 $3 \%$ 的缓坡造成了大片水深在 $1 \mathrm{~m}$ 以内的浅水区, 为以匍匐茎、横走茎为主茎主要部分的 荇菜、菱提供了合适的生长环境. 研究区 B 内 $5 \%$ 的坡度使得浅水区面积有限, 而水深 $1.0 \sim 2.0 \mathrm{~m}$ 的区域面 积较大, 为具有肥厚根状茎的睡莲提供了良好条件. 研究区 B 中的沉水植物生物量增长较快, 在 2015 年冬 季时就超过研究区 A. 在消浪带保护下水力条件的差异在研究区 $A 、 B$ 之间几乎可以忽略, 但水生植物构成 上的差异指出水位、水质以及沉积物营养条件均是潜在的影响因素.

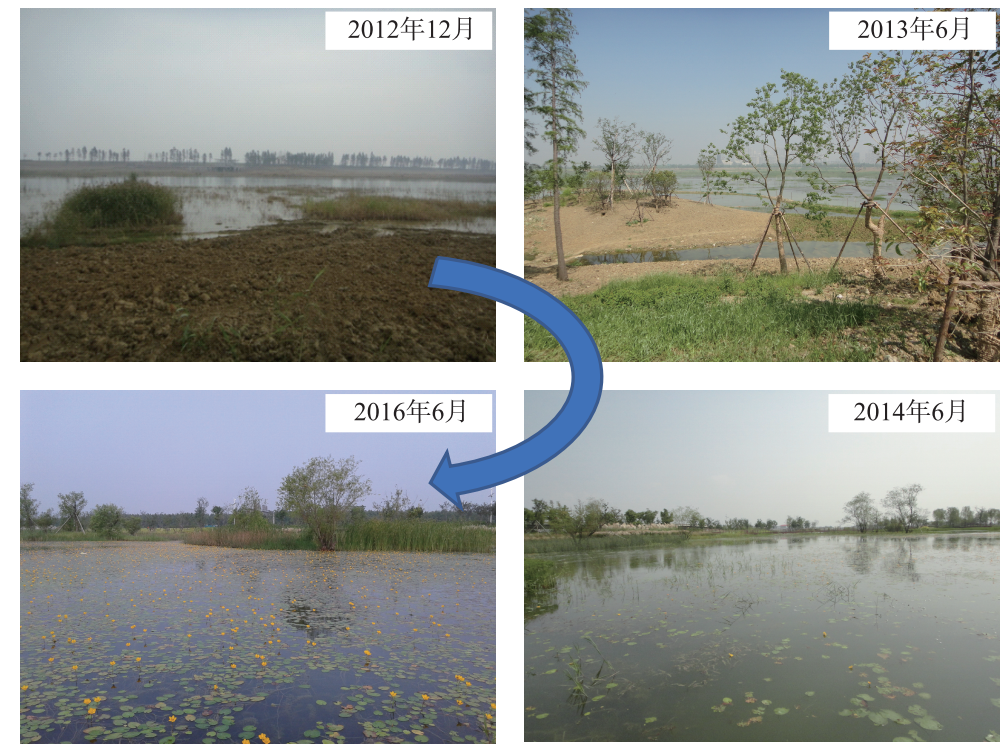

图 22012-2016 年湖滨带景观变化

Fig.2 The landscapes of lakeshore from 2012 to 2016

- 研究区A沉水植物 $\Delta$ 研究区A浮叶植物 $\square$ 研究区B沉水植物 $\Delta$ 研究区B浮叶植物
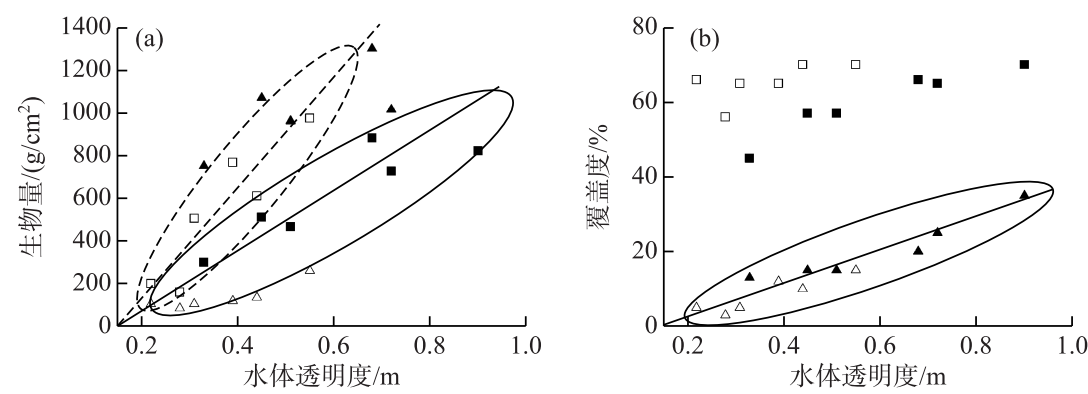

图 3 研究区水体透明度与水生植物生物量 (a)、覆盖度 (b) 分布情况

Fig.3 The distributions of macrophytes' biomass (a) and coverage (b) with water transparency in study area

\section{2 水体营养状态指数变化}

如图 4 所示, 研究区水质提高明显, 水体平均 DO 浓度由 $4.0 \mathrm{mg} / \mathrm{L}$ 增至 $8.0 \mathrm{mg} / \mathrm{L}, \mathrm{DO} 、$ Chl. $a$ 浓度持续上 升, 虽然在夏季与冬季有不同程度的反弹, 但 $\mathrm{TP} 、 \mathrm{COD}_{\mathrm{Mn}} 、 \mathrm{NH}_{3}-\mathrm{N} 、 \mathrm{TN}$ 浓度总体上持续下降. 对照区的各项指 
表 $12014-2016$ 年研究区 A、B 内水生植物覆盖度和生物量

Tab.1 Macrophyte's cover and biomass in study area A and B from 2014 to 2016

\begin{tabular}{|c|c|c|c|c|c|c|c|c|c|}
\hline \multirow{3}{*}{ 时间 } & \multirow{3}{*}{ 季节 } & \multicolumn{4}{|c|}{ 研究区 A } & \multicolumn{4}{|c|}{ 研究区 B } \\
\hline & & \multicolumn{2}{|c|}{ 浮叶植物 } & \multicolumn{2}{|c|}{ 沉水植物 } & \multicolumn{2}{|c|}{ 浮叶植物 } & \multicolumn{2}{|c|}{ 沉水植物 } \\
\hline & & $\begin{array}{c}\text { 覆盖度/ } \\
\%\end{array}$ & $\begin{array}{l}\text { 生物量/ } \\
\left(\mathrm{g} / \mathrm{cm}^{2}\right)\end{array}$ & $\begin{array}{c}\text { 覆盖度/ } \\
\%\end{array}$ & $\begin{array}{l}\text { 生物量/ } \\
\left(\mathrm{g} / \mathrm{cm}^{2}\right)\end{array}$ & $\begin{array}{c}\text { 覆盖度/ } \\
\%\end{array}$ & $\begin{array}{l}\text { 生物量/ } \\
\left(\mathrm{g} / \mathrm{cm}^{2}\right)\end{array}$ & $\begin{array}{c}\text { 覆盖度/ } \\
\%\end{array}$ & $\begin{array}{l}\text { 生物量 } \\
\left(\mathrm{g} / \mathrm{cm}^{2}\right)\end{array}$ \\
\hline \multirow[t]{2}{*}{2014 年 } & 夏季 & $15.1 \pm 3.9$ & $1070 \pm 110$ & $57.2 \pm 6.1$ & $510 \pm 65$ & $5.9 \pm 1.0$ & $105 \pm 11$ & $66.1 \pm 5.8$ & $200 \pm 31$ \\
\hline & 冬季 & $13.9 \pm 4.1$ & $750 \pm 89$ & $45.5 \pm 5.5$ & $300 \pm 42$ & $3.3 \pm 0.5$ & $85 \pm 13$ & $56.3 \pm 6.3$ & $160 \pm 22$ \\
\hline \multirow[t]{2}{*}{2015 年 } & 夏季 & $20.6 \pm 3.8$ & $1300 \pm 117$ & $66.1 \pm 6.8$ & $880 \pm 85$ & $10.6 \pm 2.3$ & $135 \pm 12$ & $70.1 \pm 4.8$ & $610 \pm 53$ \\
\hline & 冬季 & $15.6 \pm 3.3$ & $960 \pm 121$ & $57.0 \pm 5.6$ & $465 \pm 50$ & $5.5 \pm 1.3$ & $105 \pm 15$ & $65.2 \pm 5.1$ & $505 \pm 48$ \\
\hline \multirow[t]{2}{*}{2016 年 } & 夏季 & $35.3 \pm 3.5$ & $1410 \pm 81$ & $70.6 \pm 6.5$ & $820 \pm 57$ & $15.8 \pm 2.5$ & $260 \pm 13$ & $70.5 \pm 3.3$ & $973 \pm 59$ \\
\hline & 冬季 & $25.0 \pm 2.9$ & $1014 \pm 89$ & $65.3 \pm 5.5$ & $725 \pm 62$ & $12.1 \pm 2.0$ & $120 \pm 8$ & $65.0 \pm 3.9$ & $766 \pm 60$ \\
\hline
\end{tabular}

标在 2014-2016 年间没有显著变化, 说明在 2014-2016 年间外部输人营养盐和水质情况没有变化. 虽然水 生植物恢复初期研究区 $\mathrm{A} 、 \mathrm{~B}$ 在 $\mathrm{COD}_{\mathrm{Mn}} 、 \mathrm{TN} 、 \mathrm{NH}_{3}-\mathrm{N}$ 等指标方面存在差异, 可能对水生植物的恢复效果造成 影响,但研究区内氮磷水平的下降以及水质的改善是显著的.

$\square$ 研究区 $\mathrm{A} \square$ 研究区B $\square$ 对照区
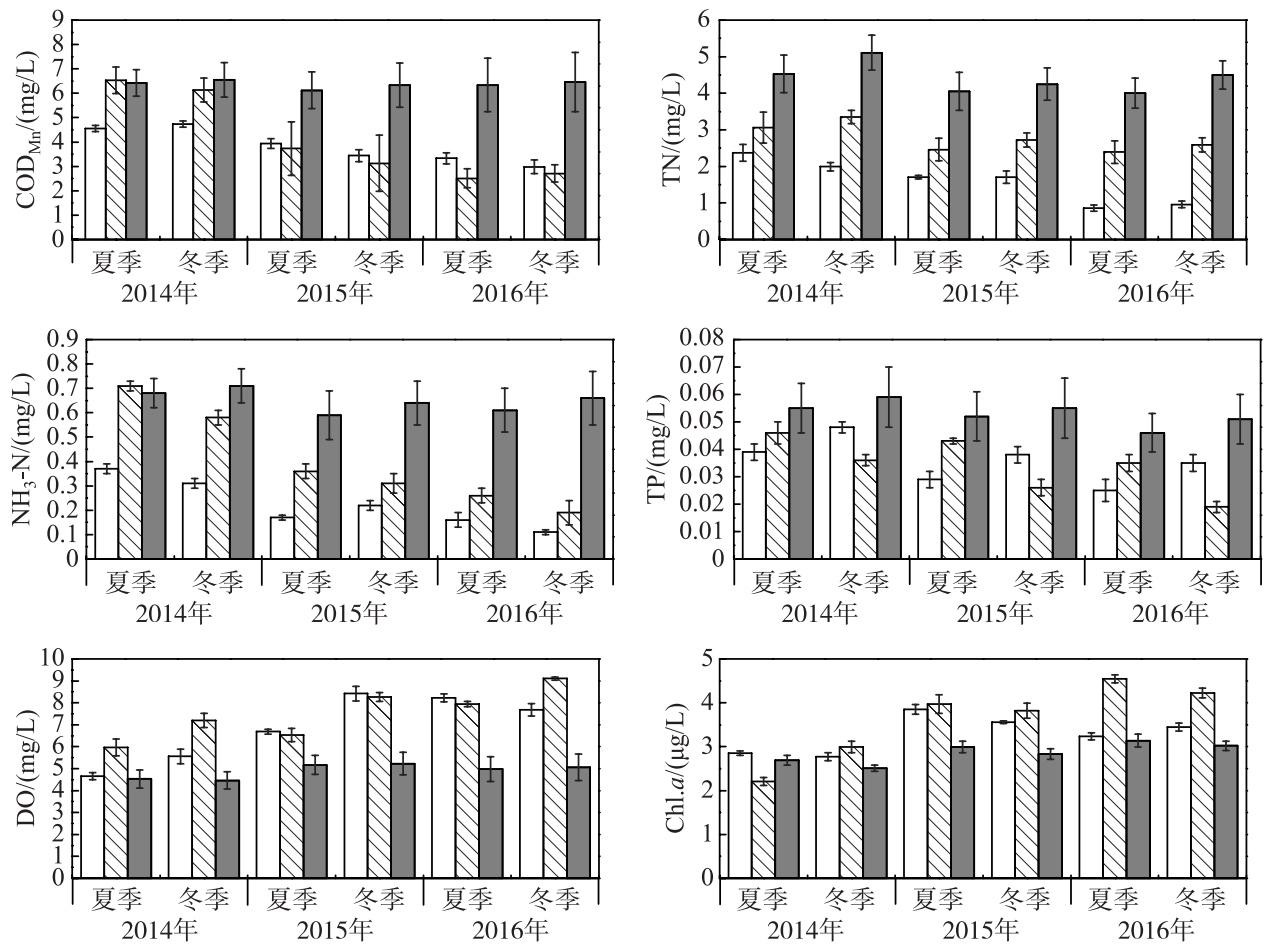

图 4 2014- 2016 年湖滨带生态修复研究区水质指标

Fig.4 Water indicators in lakeshore restoration from 2014 to 2016

水体营养状态指数 $T L I$ 将叶绿素 $a$ 浓度作为核心,与其他指标 $\left(\mathrm{TP} 、 \mathrm{TN} 、 \mathrm{SD} 、 \mathrm{COD}_{\mathrm{Mn}}\right.$ ) 在空间分布上的相 关系数 $\left(r_{i j}\right)$ 分别为 $0.84 、 0.82 、-0.83 、 0.83$, 整理后得到各指标权重如表 1 所示. 根据公式 $(6)$ 计算得到综合 营养状态指数 $T L I\left(\sum\right)$ 在修复过程中逐渐下降, 2016 年研究区 A、B 降至中营养水平 (表 2). 研究区 A 在 2014 年基本保持在富营养水平,在随后的修复过程中营养水平逐渐下降,但是年内变化情况指出冬季营养 
水平要略高于夏季, 总磷成为影响其综合得分的重要因素. 研究区 B 在 2014、2015 年基本维持在富营养水 平,2016 年逐渐达到中营养水平, 总磷、叶绿素 $a$ 浓度虽有季节性的回升,但总体在平稳下降. 对照区内的水 体 $T L I$ 值一直处于富营养水平,透明度、总氮以及化学需氧量得分高于研究区.

表 2 2014-2016 年夏季和冬季 Chl. $a$ 、TP、TN、SD、COD ${ }_{\mathrm{Mn}}$ 营养状态指数 $(T L I)$ 及综合营养状态指数 $T L I\left(\sum\right)$ *

Tab.2 Trophic level index $(T L I)$ for the water indicators (Chl. $a$, TP, TN, SD, COD ${ }_{\mathrm{Mn}}$ ) and the $\operatorname{TLI}\left(\sum\right)$ values in summer and winter from 2014 to 2016

\begin{tabular}{ccccccccc}
\hline 区域 & 时间 & $T L I(\mathrm{Chl} . a)$ & $T L I(\mathrm{TP})$ & $T L I(\mathrm{TN})$ & $T L I(\mathrm{SD})$ & $T L I\left(\mathrm{COD}_{\mathrm{Mn}}\right)$ & $T L I\left(\sum\right)$ & 营养水平 \\
\hline 研究区 A & 2014 年夏季 & 36.4 & 41.6 & 69.2 & 66.6 & 41.4 & 49.7 & Mesotrophic(中营养) \\
& 2014 年冬季 & 36.0 & 45.0 & 66.2 & 72.6 & 42.5 & 51.0 & Eutrophic(富营养) \\
& 2015 年夏季 & 39.6 & 36.8 & 63.6 & 58.6 & 37.6 & 46.5 & Mesotrophic(中营养) \\
& 2015 年冬季 & 38.8 & 41.2 & 63.6 & 64.2 & 34.0 & 47.4 & Mesotrophic(中营养) \\
& 2016 年夏季 & 37.8 & 34.4 & 52.0 & 53.2 & 33.1 & 41.6 & Mesotrophic(中营养) \\
& 2016 年冬季 & 38.4 & 39.9 & 53.8 & 57.6 & 30.1 & 43.4 & Mesotrophic(中营养) \\
研究区 B $\mathrm{B}$ & 2014 年夏季 & 33.6 & 44.4 & 73.4 & 80.6 & 51.0 & 54.6 & Eutrophic(富营养) \\
& 2014 年冬季 & 36.8 & 40.4 & 75.0 & 75.8 & 49.4 & 53.8 & Eutrophic(富营养) \\
& 2015 年夏季 & 40.0 & 43.2 & 69.8 & 67.1 & 36.1 & 50.2 & Eutrophic(富营养) \\
& 2015 年冬季 & 39.6 & 35.1 & 71.5 & 73.9 & 31.4 & 49.2 & Mesotrophic(中营养) \\
& 2016 年夏季 & 41.4 & 39.9 & 69.3 & 62.8 & 25.6 & 47.1 & Mesotrophic(中营养) \\
& 2016 年冬季 & 40.6 & 30.0 & 70.6 & 69.4 & 27.6 & 46.9 & Mesotrophic(中营养) \\
对照区 & 2014 年夏季 & 35.8 & 47.2 & 80.1 & 78.1 & 50.6 & 56.3 & Eutrophic(富营养) \\
& 2014 年冬季 & 35.0 & 48.4 & 82.2 & 83.4 & 51.1 & 57.8 & Eutrophic(富营养) \\
& 2015 年夏季 & 36.9 & 46.4 & 78.2 & 82.4 & 49.3 & 56.6 & Eutrophic(富营养) \\
& 2015 年冬季 & 36.3 & 47.2 & 79.0 & 81.4 & 50.2 & 56.8 & Eutrophic(富营养) \\
& 2016 年夏季 & 37.4 & 44.4 & 78.0 & 78.1 & 50.2 & 55.8 & Eutrophic(富营养) \\
2016 年冬季 & 37.0 & 46.0 & 80.0 & 81.4 & 50.7 & 57.0 & Eutrophic(富营养) \\
\hline
\end{tabular}

* TLI ( Chl. $a) 、 T L I(\mathrm{TP}) 、 T L I(\mathrm{TN}) 、 T L I(\mathrm{SD}) 、 T L I\left(\mathrm{COD}_{\mathrm{Mn}}\right) 、 T L I(\Sigma)$ 权重分别为 $0.266 、 0.188 、 0.179 、 0.183 、 0.183 、 1$.

\section{3 表层沉积物营养水平}

表层沉积物 $(0 \sim 5 \mathrm{~cm})$ 不仅是氮、磷等营养物质在水体一沉积物之间交换的重要场所,还是湖泊生态系 统中水生植物、底栖生物、微生物的重要栖息场所. 表层沉积物赋存的有机物、氮、磷等营养物质是整个湖泊 生态系统潜在的承载力, 以及水生植物重要的营养盐来源. 表层沉积物在基底构建阶段(2012 年) 主要由当 地沙壤土构成, 水位恢复后 (2013 年) 还有沉淀带来的新生底质. 如表 3 所示, 修复初期( 2014 年) 研究区内 的表层沉积物中有机物含量为 $30 \% 0 \sim 50 \%$, N 含量为 $1.5 \sim 2.3 \mathrm{mg} / \mathrm{g}, \mathrm{P}$ 含量为 $0.16 \sim 0.21 \mathrm{mg} / \mathrm{g}$. 随着水生植 物恢复存在不同程度的下降, 沉积物 $\mathrm{N}$ 含量迅速下降, 在研究区 A 内由 $1.50 \mathrm{mg} / \mathrm{g}$ 降至 $0.56 \mathrm{mg} / \mathrm{g}$, 在研究 区 $\mathrm{B}$ 内由 $2.31 \mathrm{mg} / \mathrm{g}$ 降至 $1.56 \mathrm{mg} / \mathrm{g}$, 研究区内沉积物 $\mathrm{P}$ 含量没有显著变化. 对照区沉积物氮、磷含量小幅上 升. 研究区内的 $B P I$ 指数由 2014 年 4.80 降至 2015 年 $2.41,2016$ 年稍有回升至 2.45 (表 3 ). 根据 $B P I$ 评分标 准, 湖滨带正在从富营养转变为中营养, 这与研究区内水体 $T L I$ 显示的营养变化情况相似. 对照区 $B P I$ 指数 由修复初期的 3.41 逐渐升至 4.00 , 修复期间一直处于富营养水平. 该结果指出成规模的水生植物恢复消耗 了沉积物中赋存的营养盐, 降低了整个湖滨生态系统富营养化的风险. 当水生植物恢复比较成熟时, 并不会 进一步降低湖滨带潜在的生态承载力, $B P I$ 会达到一个相对稳定的状态.

\section{4 浮游藻类的变化}

夏季是浮游植物生长繁殖旺盛的时期, 研究区 A 内主要由蓝藻门平裂藻属 (Merismopedia)、绿藻门十字 藻属 (Crucigenia)、硅藻门直链条藻属 (Melosira) 构成, 研究区 B 内主要由蓝藻门颤藻属 (Oscillatoria)、绿藻 门十字藻属 (Crucigenia)、蓝藻门平裂藻属 (Merismopedia)、蓝藻门鱼腥藻属 (Anabaena) 组成. 研究区内浮游 植物主要种类占总密度的 $90 \%$ 以上, 而具体的构成情况如图 5 所示. 湖滨带水体与太湖贡湖湾主体相连, 在 修复初期就形成了蓝藻为优势种群的格局. 从修复初期(2014 年 6 月)至后期(2016 年 6 月), 研究区 A 内一 
表 $32014-2016$ 年研究区 A、B 表层沉积物年均有机物 (IG) 含量、

$\mathrm{N}$ 含量、 $\mathrm{P}$ 含量以及生物生产力指数 $(B P I)$

Tab.3 Annual mean contents of organic matter( IG), nitrogen and phosphorus in the surface sediment of study area A, B and the bioproduction index (BPI) from 2014 to 2016

\begin{tabular}{|c|c|c|c|c|c|c|c|c|}
\hline \multirow{2}{*}{ 年份 } & \multicolumn{2}{|c|}{ 有机物含量/\%o } & \multicolumn{2}{|c|}{$\mathrm{N}$ 含量/( mg/g) } & \multicolumn{2}{|c|}{$\mathrm{P}$ 含量/ (mg/g) } & \multirow{2}{*}{ 回归线 } & \multirow{2}{*}{$B P I$} \\
\hline & 研究区 A & 研究区 B & 研究区 A & 研究区 B & 研究区 A & 研究区 B & & \\
\hline 2014 & $37.00 \pm 2.80$ & $41.50 \pm 3.30$ & $1.50 \pm 0.10$ & $2.31 \pm 0.20$ & $0.16 \pm 0.01$ & $0.21 \pm 0.03$ & $N=0.045 I G+0.30, r=0.80$ & 4.80 \\
\hline 2015 & $34.50 \pm 2.30$ & $42.10 \pm 4.10$ & $0.62 \pm 0.05$ & $1.55 \pm 0.15$ & $0.16 \pm 0.02$ & $0.17 \pm 0.03$ & $N=0.025 I G-0.09, r=0.71$ & 2.41 \\
\hline 2016 & $30.00 \pm 1.00$ & $46.10 \pm 5.60$ & $0.56 \pm 0.34$ & $1.56 \pm 0.13$ & $0.18 \pm 0.02$ & $0.18 \pm 0.02$ & $N=0.025 I G-0.05, r=0.73$ & 2.45 \\
\hline 年份 & \multicolumn{2}{|c|}{ 对照区 } & \multicolumn{2}{|c|}{ 对照区 } & \multicolumn{2}{|c|}{ 对照区 } & 回归线 & $B P I$ \\
\hline 2014 & \multicolumn{2}{|c|}{$50.00 \pm 4.60$} & \multicolumn{2}{|c|}{$1.71 \pm 0.33$} & \multicolumn{2}{|c|}{$0.19 \pm 0.11$} & $N=0.035 I G-0.09, r=0.85$ & 3.41 \\
\hline 2015 & \multicolumn{2}{|c|}{$53.00 \pm 5.50$} & \multicolumn{2}{|c|}{$1.93 \pm 0.45$} & \multicolumn{2}{|c|}{$0.26 \pm 0.09$} & $N=0.036 I G+0.30, r=0.80$ & 3.90 \\
\hline 2016 & \multicolumn{2}{|c|}{$47.00 \pm 5.10$} & \multicolumn{2}{|c|}{$1.81 \pm 0.39$} & \multicolumn{2}{|c|}{$0.20 \pm 0.07$} & $N=0.039 I G+0.10, r=0.80$ & 4.00 \\
\hline
\end{tabular}

直以蓝藻门平裂藻属为最优势浮游植物, 其占比一直升高, 而绿藻门十字藻属的占比则持续下降. 研究区 $\mathrm{B}$ 内浮游植物群落结构发生了显著变化, 蓝藻门平裂藻属占比持续上升, 2016 年夏季时已经成为最优势种群, 绿藻占比则快速下降, 2016 年夏季时已不再是主要种群. 总体上看, 蓝藻逐渐占据优势, 绿藻、硅藻则逐渐衰 退. 研究区 A 内藻类密度在 2015 年达到最高后下降, 研究区 B 内藻类密度也有相似变化趋势. 研究区 A、B 内浮游植物种类存在差异, 变化趋势却大致相同, 即总密度得到控制, 但是种群结构也愈发单一. 对照区内 浮游植物也由上述藻类构成主要种群, 密度也维持在 $2.5 \times 10^{5} \sim 3.0 \times 10^{5} \mathrm{cells} / \mathrm{L}$ 左右, 但是群落结构在 20142016 年间没有显著变化, 主要种群占比均在 $20 \%$ 30\% 之间. 蓝藻在研究区逐渐取得优势地位, 氮磷水平下 降造成的竞争, 以及水生植物对水下光照、溶解氧的影响都有可能造成此类结果.
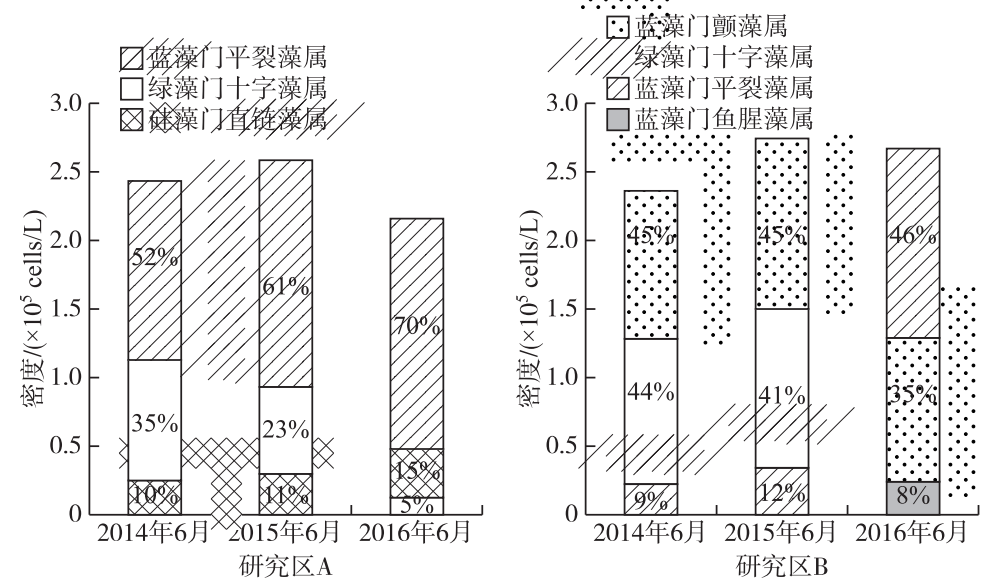

图 5 研究区 $A 、 B$ 内主要浮游植物密度及占比

Fig.5 The main phytoplankton species' density and proportions in study area A and B

\section{3 讨论}

水生植物的生长受到水深、水质的影响, 研究区 $\mathrm{A} 、 \mathrm{~B}$ 水生植物群落恢复情况的不同是两处水深、水质上 差异的结果. 如表 4 所示水深与浮叶植物的覆盖度呈反比 (Pearson's $r=-0.630, P<0.1$ ), 与沉水植物的生物 量呈正比 (Pearson's $r=0.598, P<0.1)$. 正如 2.1 节反映的情况一样, 研究区 A 内相对广阔的浅水区为丰富 的浮叶植物群落提供了条件, 而研究区 $\mathrm{B}$ 内 $1 \sim 2 \mathrm{~m}$ 水深的区域更利于沉水植物的生长. 同时水体总氮、氨氮 
浓度与水生植物指标存在显著的负相关 (详见表 4), 图 6 还显示总氮浓度与浮叶植物覆盖度有良好的线性 负相关关系, 即浮叶植物覆盖度从空间、时间上看均与总氮呈反比. 相关研究也发现高氨态氮胁迫下水生植 物生理机能有显著的减弱 ${ }^{[31]}$. 研究区 B 初期较高的总氮 $(>3.0 \mathrm{mg} / \mathrm{L})$ 、氨氮 $(>0.6 \mathrm{mg} / \mathrm{L})$ 浓度以及较深水位 (1 2 m) 综合作用下造成了浮叶植物在相同的栽种总类和密度下恢复情况不如研究区 $A$, 其中荇菜、菱对总 氮、氨氮相较于睡莲更为敏感.

表 4 2014-2016 年研究区内水深,水质指标 $\left(\mathrm{SD} 、 \mathrm{COD}_{\mathrm{Mn}} 、 \mathrm{TN} 、 \mathrm{NH}_{3}-\mathrm{N} 、 \mathrm{TP} 、 \mathrm{Chl} . a\right)$ 与

浮游藻类、水生植物指标的相关性分析

Tab.4 The relationships of water depth and quality indicators ( $\mathrm{SD}, \mathrm{COD}_{\mathrm{Mn}}, \mathrm{TN}, \mathrm{NH}_{3}-\mathrm{N}, \mathrm{TP}$, Chl.a) with phytoplankton, macrophyte indicators in study area from 2014 to 2016

\begin{tabular}{|c|c|c|c|c|c|c|c|c|c|c|c|c|c|c|}
\hline & 水深 & SD & $\mathrm{COD}_{\mathrm{Mn}}$ & $\mathrm{TN}$ & $\mathrm{TP}$ & $\mathrm{NH}_{3}-\mathrm{N}$ & Chl. $a$ & $\begin{array}{l}\text { 蓝藻 } \\
\text { 数量 }\end{array}$ & $\begin{array}{l}\text { 绿藻 } \\
\text { 数量 }\end{array}$ & $\begin{array}{l}\text { 硅藻 } \\
\text { 数量 }\end{array}$ & $\begin{array}{c}\text { 浮叶植 } \\
\text { 物覆 } \\
\text { 盖度 }\end{array}$ & $\begin{array}{c}\text { 浮叶植 } \\
\text { 物生 } \\
\text { 物量 }\end{array}$ & $\begin{array}{c}\text { 沉水植 } \\
\text { 物覆 } \\
\text { 盖度 }\end{array}$ & $\begin{array}{c}\text { 沉水植 } \\
\text { 物生 } \\
\text { 物量 }\end{array}$ \\
\hline 水深 & 1 & 0.510 & 0.113 & 0.230 & 0.180 & 0.245 & 0.311 & 0.203 & 0.080 & 0.127 & $-0.630^{*}$ & -0.512 & 0.495 & $0.598 *$ \\
\hline $\mathrm{SD}$ & & 1 & -0.556 & $-0.892 * *$ & -0.398 & $-0.751^{* * *}$ & 0.303 & 0.055 & -0.563 & 0.072 & $0.957^{\text {*** }}$ & $0.781^{* *}$ & 0.421 & $0.745^{\text {*** }}$ \\
\hline $\mathrm{COD}_{\mathrm{Mn}}$ & & & 1 & 0.526 & $0.587^{*}$ & $0.874^{* *}$ & -0.835 ** & $-0.724^{\text {** }}$ & * $0.925^{\text {*** }}$ & 0.095 & -0.486 & -0.203 & -0.415 & $-0.829^{* *}$ \\
\hline $\mathrm{TN}$ & & & & 1 & 0.196 & $0.791^{* *}$ & -0.120 & 0.115 & 0.483 & -0.221 & $-0.935^{* *}$ & $-0.842 * *$ & -0.130 & -0.551 * \\
\hline TP & & & & & 1 & 0.541 & $-0.564^{*}$ & $-0.510 *$ & $0.609^{*}$ & 0.232 & -0.320 & -0.097 & -0.457 & -0.586 * \\
\hline $\mathrm{NH}_{3}-\mathrm{N}$ & & & & & & 1 & $-0.618^{*}$ & -0.367 & $0.754^{* *}$ & -0.200 & $-0.725^{\text {** }}$ & -0.581 * & -0.178 & $-0.782^{* *}$ \\
\hline Chl. $a$ & & & & & & & 1 & $0.883^{* *}$ & $-0.780^{* *}$ & -0.164 & 0.127 & -0.143 & 0.504 & $0.768^{* * *}$ \\
\hline 蓝藻数量 & & & & & & & & 1 & $-0.791^{* *}$ & $-0.467 *$ & -0.054 & -0.450 & $0.577^{*}$ & $0.633 *$ \\
\hline 绿藻数量 & & & & & & & & & 1 & 0.415 & -0.509 & -0.064 & -0.604 * & -0.831 ** \\
\hline 硅藻数量 & & & & & & & & & & 1 & 0.107 & $0.587^{*}$ & -0.557 & -0.060 \\
\hline $\begin{array}{c}\text { 浮叶植物 } \\
\text { 覆盖度 }\end{array}$ & & & & & & & & & & & 1 & $0.834^{* * *}$ & 0.269 & $0.646^{*}$ \\
\hline $\begin{array}{c}\text { 浮叶植物 } \\
\text { 生物量 }\end{array}$ & & & & & & & & & & & & 1 & -0.104 & 0.361 \\
\hline $\begin{array}{c}\text { 沉水植物 } \\
\text { 覆盖度 }\end{array}$ & & & & & & & & & & & & & 1 & $0.635^{*}$ \\
\hline $\begin{array}{c}\text { 沉水植物 } \\
\text { 生物量 }\end{array}$ & & & & & & & & & & & & & & 1 \\
\hline
\end{tabular}

*表示 $P<0.05, * *$ 表示 $P<0.01$.

为了减少人为干扰, 实验期间除了少量的采集监测, 没有实施水生植物的收割. 冬季水生植物枯萎可能 导致部分同化的氮磷返回到湖滨带生境中,但是在研究区生境中并没有出现冬季氮磷含量的普遍上升. 氮、 磷总体上由湖滨带生境通过水生植物、浮游藻类向湖滨生态系统累计. 随着水生植物的生长, 湖滨生境中的 氮磷浓度得到了控制. 图 7 综合反映了研究区水体/沉积物氮均有不同程度的下降, 而对照区内, 水体总氮 浓度在 4 5 mg/L 之间, 沉积物平均氮含量则由 $1.71 \mathrm{mg} / \mathrm{g}$ 上升至 $1.81 \mathrm{mg} / \mathrm{g}$, 外界输人的氮逐渐累计在沉积 物中. 相关研究指出水生植物主要通过根系吸收沉积物中的营养盐, 间接控制上覆水体中的氮浓度 ${ }^{[32]}$. 水 体总氮浓度与浮叶植物覆盖度、沉水植物生物量存在负线性关系 (图 6), 反映出这两类水生植物的关键生长 指标直接响应了水体总氮情况. 水生植物即可以通过根系吸收沉积物中的有效氮, 也可以直接利用水体中 硝酸盐、亚硝酸盐、氨氮等溶解性氮 ${ }^{[33-34]}$. 研究区内沉积物氮逐年下降, 水体总氮在水生植物的影响下直接 下降, 反映出水生植物在吸收沉积物中氮的同时, 也在直接利用水中部分有效氮. 水生植物在生长过程中受 到总氮/氨氮浓度的影响, 但是在形成成熟稳定的群落后可以有效固氮, 减少了输人型氮在生境中的累计.

如图 7 所示, 研究区水体总磷浓度逐年下降,但研究区 A 夏季水体总磷浓度要低于冬季, 研究区 $\mathrm{B}$ 夏季 水体总磷浓度则要高于冬季. 总磷浓度除了与沉水植物生物量存在负相关性, 还与叶绿素 $a$ 浓度 (Pearson's $r=-0.564, P<0.1)$ 、蓝藻数量 ( Pearson's $r=-0.501, P<0.1)$ 、绿藻数量 (Pearson's $r=-0.609, P<0.1)$ 存在显 

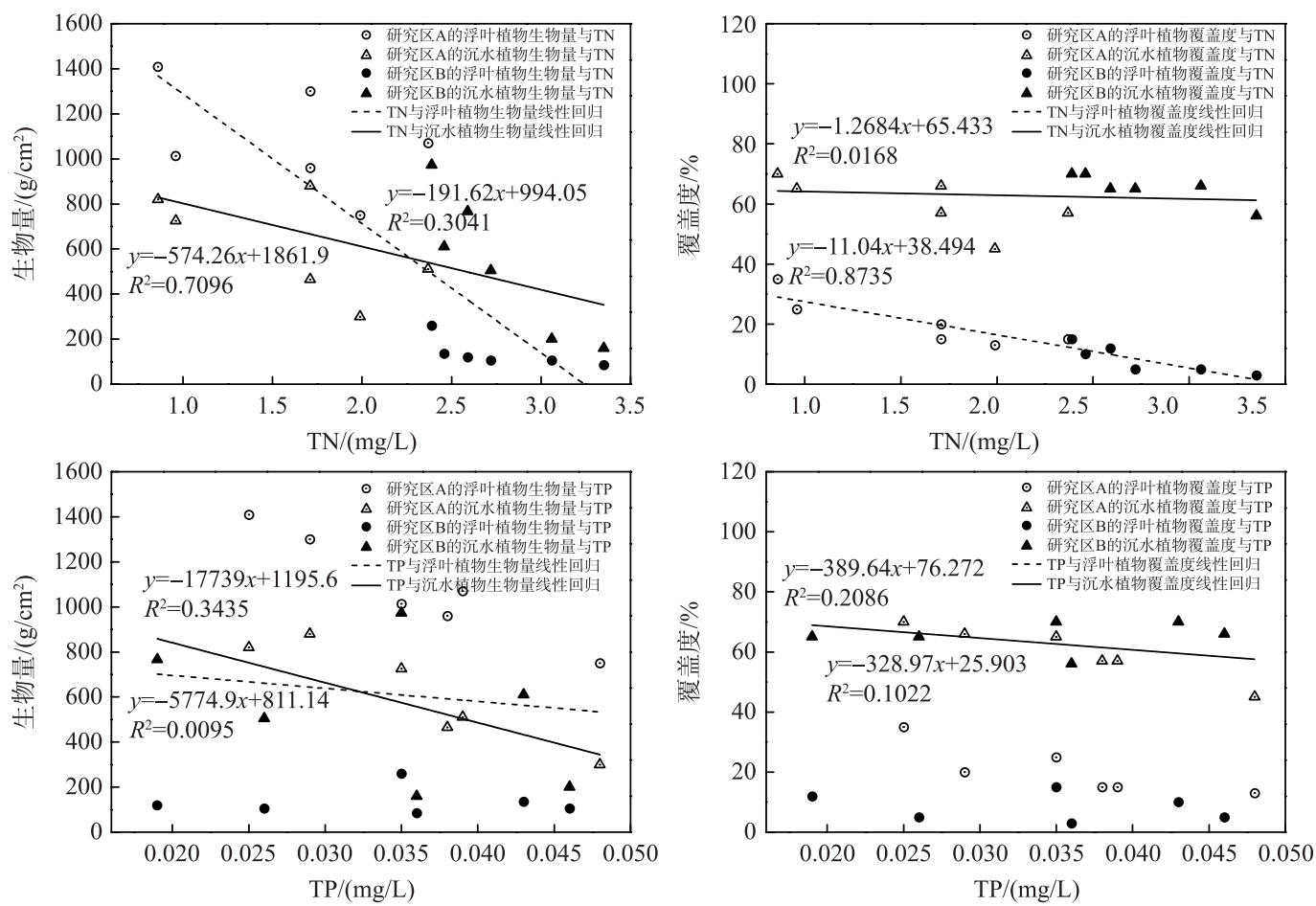

图 6 2014-2016 年水体 TN、TP 浓度与水生植物生物量、覆盖度的线性回归

Fig. 6 Linear regressions between the TN, TP concentration and the macrophyte biomasses, covers from 2014 to 2016

著负相关性 (表 4). 以上统计分析结果显示随着浮游藻类活动增强, 其对水体磷吸收的能力也增强. 实际上 相关研究已经指出浮游澡类与水生植物对磷酸盐有竞争性吸收, 并且对磷有更敏感的反应, 湖泊中往往呈 现出磷驱动下的藻类活动规律 ${ }^{[35-36]}$. 研究区水体总磷的季节性差异来自于浮游藻类群落的不同, 根据浮游 藻类调查结果 (详见 2.4 节), 研究区 A、B 内蓝藻一直处于优势地位, 但研究区 A 以平裂藻属为主, 研究区 B 内颤藻为重要组成部分. 相关研究指出水生植物通过改变光照、溶解氧以及 $\mathrm{pH}$ 等理化条件对浮游植物群落 结构有直接影响 ${ }^{[36]}$. 颤藻对磷的高效吸收利用往往使其在富营化浅水湖泊中占据优势 ${ }^{[37]}$. 在研究区 B 内颤 藻作为优势种在冬季其他藻类对磷吸收效率下降时仍能有效吸收水体中的磷, 造成了上述水体总磷浓度季 节性的差异. 相关研究发现平裂藻喜碱性环境, 能够高效吸收氮, 但对磷的吸收利用要低于其他蓝藻 ${ }^{[38]}$. 广 泛存在于研究区 $\mathrm{A}$ 的平裂藻在冬季对磷的吸收利用效果低于颤藻, 对照区内各类蓝藻、绿藻、硅藻比例相 近, 没有明显的优势种, 虽然随着藻类活动逐渐增强, 叶绿素 $a$ 浓度升高, 水体总磷浓度略有下降, 也出现了 冬季总磷浓度高于夏季的现象. 但与研究区不同的是对照区年均总磷水平没有显著变化, 沉积物中磷含量 还略有升高. 对比研究区与对照区, 可以发现水生植物与浮游藻类共同吸收利用环境中的磷, 浮游藻类会相 比水生植物会更直接地同化利用水环境中的磷, 而水生植物主要针对沉积物磷进行吸收利用. 考虑到水生 植物对浮游藻类群落的影响,水生植物在湖滨区域起到了良好控磷作用.

\section{4 结论}

构建合适的生境是人工湖滨带水生植物修复的首要条件. 在减少水力扰动前提下,水位、水质对水生植 物的恢复有着显著的影响. 以荇菜、睡莲、菱为代表的浮叶植物群落受水深、水质的影响相比以黑藻、小眼子 菜、竹叶眼子菜为代表的沉水植物更为明显. 较高浓度的总氮 $(>3.0 \mathrm{mg} / \mathrm{L})$ 、氨氮 $(>0.6 \mathrm{mg} / \mathrm{L})$ 环境会抑制浮 叶植物的生长, 而沉水植物则表现出更好的适应性. 随着水生植物的恢复, 水体、沉积物中氮磷营养物质逐 

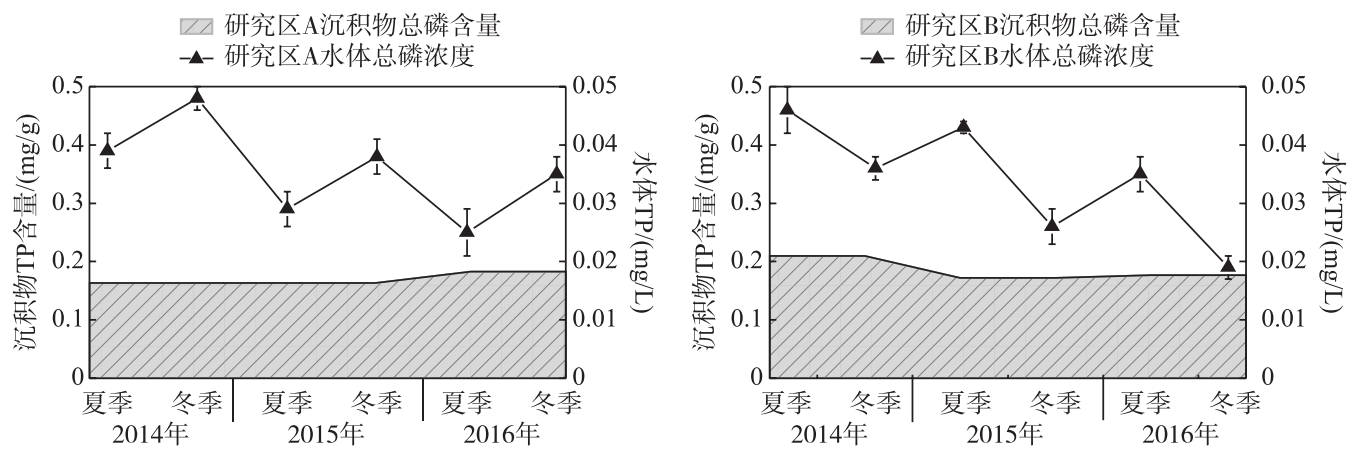

Z7 研究区A沉积物总氮含量

- - - 研究区A水体总氮浓度

- 研究区A水体氨氮浓度
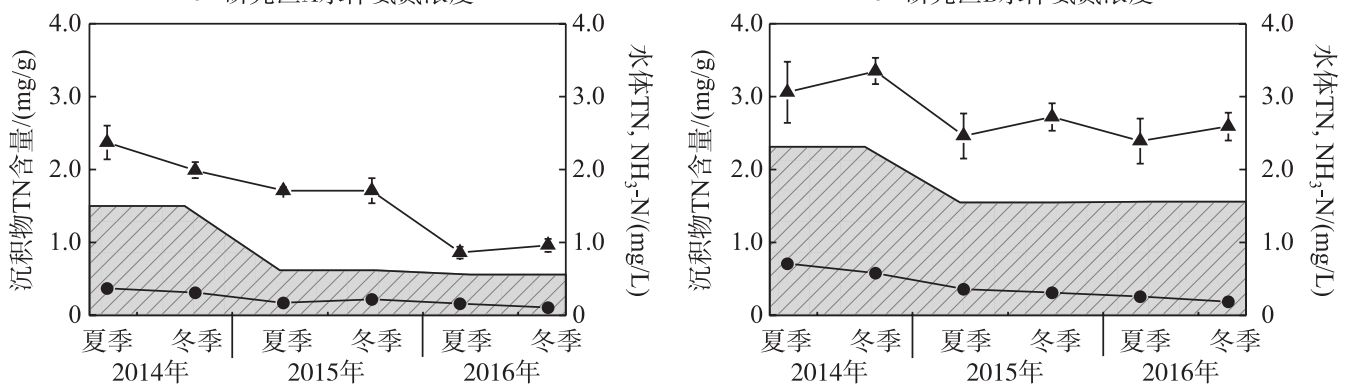

图 $72014-2016$ 年研究区 $\mathrm{A} 、 \mathrm{~B}$ 水体 $\mathrm{TP} 、 \mathrm{TN} 、 \mathrm{NH}_{3}-\mathrm{N}$ 浓度和沉积物 TP、TN 含量

Fig.7 TP, TN, $\mathrm{NH}_{3}-\mathrm{N}$ concentration in water, and TP, TN contents in surface sediment of study area A, B from 2014 to 2016

年减少,水体 $T L I$ 、沉积物 $B P I$ 值显著下降, 水体透明度显著提升.

水生植物在氮、磷控制的方式上存在显著的差异. 虽然水生植物可以从湖滨带生境中吸收利用氮磷营 养元素, 尤其显著降低了水体总氮、氨氮浓度, 但是对水体总磷的直接吸收有限. 研究发现浮游澡类活动的 增强减少了水体总磷浓度, 冬季颤藻相对直裂藻及其他绿藻、硅藻更高效地吸收利用水体中的磷, 造成了研 究区年均总磷浓度持续下降的背景下季节性的差异. 水生植物可能正是通过影响藻类构成的方式间接地控 制水体总磷. 总结上述结论,恢复一个丰富的水生植物群落在湖滨区域作为控制氮磷的有效办法可以缓解 湖泊的富营化趋势,但水生植物与浮游藻类之间的互动和影响仍是其作为工程技术手段需要扩展考察的 方面.

\section{5 参考文献}

[ 1 ] Palmer MA, Filoso S, Fanelli RM. From ecosystems to ecosystem services: Stream restoration as ecological engineering. Ecological Engineering, 2014, 65: 62-70.

[ 2 ] Ye C, Li CH, Wu L et al. Ecological degradation of lake littoral zone and interaction effects with human activities. Research of Environmental Sciences, 2015, 28(3) : 401-407. [叶春, 李春华, 吴蕾等. 湖滨带生态退化及其与人类活动 的相互作用. 环境科学研究, 2015, 28(3): 401-407.]

[ 3 ] Yu H. Ecosystem restoration and regeneration of lake Biwa basin, Japan. Research of Environmental Sciences, 2016,29 (1) : 36-43. [余辉. 日本琵琶湖流域生态系统的修复与重建. 环境科学研究, 2016, 29(1): 36-43.]

[ 4 ] Krolová M, Čižková H, Hejzlar J. Depth limit of littoral vegetation in a storage reservoir: A case study of Lipno Reservoir (Czech Republic). Limnologica, 2012, 42(2) : 165-174. DOI: 10.1016/j.limno.2011.10.002.

[ 5 ] Palmer ME, Winter JG, Young JD et al. Introduction and summary of research on Lake Simcoe: Research, monitoring, 
and restoration of a large lake and its watershed. Journal of Great Lakes Research, 2011, 37: 1-6. DOI: 10.1016/j.jglr. 2011.04.003.

[ 6 ] Kong XZ, Jørgensen SE, He W et al. Predicting the restoration effects by a structural dynamic approach in Lake Chaohu, China. Ecological Modelling, 2013, 266: 73-85. DOI: 10.1016/j.ecolmodel.2013.07.001.

[ 7 ] Huang L, Shao QQ, Liu JY. Forest restoration to achieve both ecological and economic progress, Poyang Lake basin, China. Ecological Engineering, 2012, 44: 53-60. DOI: 10.1016/j.ecoleng.2012.03.007.

[ 8 ] Ye C, Li CH, Yu HC et al. Study on ecological restoration in near-shore zone of a eutrophic lake, Wuli Bay, Taihu Lake. Ecological Engineering, 2011, 37(9) : 1434-1437. DOI: 10.1016/j.ecoleng.2011.03.028.

[ 9 ] Zhang YY, Cai XB, Yang C et al. Driving force analysis of landscape pattern changes in Honghu Wetland Nature Reserve in recent 40 years. J Lake Sci, 2019, 31(1) : 171-182. DOI: 10.18307/2019.0116. [张荣芗, 蔡晓斌, 杨超等. 19742017 年洪湖湿地自然保护区景观格局演变及驱动力分析. 湖泊科学, 2019, 31(1) : 171-182.]

[10] Xie J, Wu DY, Chen XC et al. Relationship between aquatic vegetation and water quality in littoral zones of Lake Dianchi and Lake Erhai. Environmental Science \& Technology, 2013, 36(2) : 55-59. [谢杰, 吴德意, 陈雪初等. 滇池和洱海湖 滨带水生植被状况与水质的关系研究. 环境科学与技术, 2013, 36(2): 55-59.]

[11] Ye C, Yu HC, Kong HN et al. Community collocation of four submerged macrophytes on two kinds of sediments in Lake Taihu, China. Ecological Engineering, 2009, 35(11) : 1656-1663. DOI: 10.1016/j.ecoleng.2008.05.008.

[12] Qi MX, Wang HP, Chen J. Decomposition of Phragmites australis and Typha angustifolia and their effects on the water quality in winter and spring. J Lake Sci, 2017, 29(2) : 420-429. DOI: 10.18307/2017.0218. [戚美侠, 王红萍, 陈杰. 冬、春季芦苇 (Phragmites australis) 和狭叶香蒲 (Typha angustifolia) 的腐解过程及其对水质的影响. 湖泊科学, $2017,29(2)$ : 420-429.]

[13] Huang DP, He F, Xiao L et al. Response between aerenchyma and radial oxygen loss of Acorus calamus Linn. under high nitrogen and phosphorus stress. J Lake Sci, 2012, 24(1) : 83-88. DOI: 10.18307/2012.0111. [黄丹萍, 贺锋, 肖蕾等. 高氦磷胁迫下菖蒲 (Acorus calamus Linn.) 通气组织和根系释氧的响应. 湖泊科学, 2012, 24(1) : 83-88.]

[14] Wan XH, Li XD, Wang YC et al. Simulation of removal ammonia and nitrate from wetlands constructed by different hydrophytes. J Lake Sci, 2008, 20(3) : 327-333. DOI : 10.18307/2008.0310. [万晓红, 李旭东, 王雨春等. 不同水生植物 对湿地无机氮素去除效果的模拟. 湖泊科学, 2008, 20(3): 327-333.]

[15] Yuan CB, Zhu TS, Cao T et al. Antioxidant systems of aquatic macrophytes in three life forms: A case study in Lake Erhai, China. Journal of Oceanology and Limnology, 2019, 37(2) : 665-674. DOI: 10.1007/s00343-019-8025-0.

[16] Ye BB, Chu ZS, Wu AP et al. Optimum water depth ranges of dominant submersed macrophytes in a natural freshwater lake. PLoS One, 2018, 13(3) : e0193176. DOI: 10.1371/journal.pone.0193176.

[17] Yu JH, Zhong JC, Chen QW et al. An investigation of the effects of capping on internal phosphorus release from sediments under rooted macrophytes (Phragmites australis) revegetation. Environmental Science and Pollution Research, 2018,25 (25) : 24682-24694. DOI: 10.1007/s11356-018-2432-1.

[18] Zhao K, Li ZG, Wei HN et al. The distribution of aquatic vegetation in Gonghu Bay, Lake Taihu, 2012. J Lake Sci, 2015, 27(3) : 421-428. DOI: 10.18307/2015.0308. [赵凯, 李振国, 魏宏农等. 太湖贡湖湾水生植被分布现状 (2012 年). 湖泊科学, 2015, 27(3): 421-428.]

[19] Deng JC, Chen Q, Zhai SJ et al. Spatial distribution characteristics and environmental effect of N and P in water body of Taihu lake. Environmental Science, 2008, 29(12) : 3382-3386. DOI: 10.13227/j.hjkx.2008.12.038. [邓建才, 陈桥, 翟水晶等. 太湖水体中氮、磷空间分布特征及环境效应. 环境科学, 2008, 29(12): 3382-3386.]

[20] Stehman SV, Overton WS. 9 Environmental sampling and monitoring. Handbook of Statistics, 1994, 12: 263-306. DOI: 10.1016/S0169-7161 ( 05 ) 80011-2.

[21] Fishman MJ, Erdmann DE, Garbarino JR. Water analysis. Analytical Chemistry, 1983, 55 ( 5) : 102-133. DOI: 10. 1021/ac00256a009.

[22] Carlson RE. A trophic state index for lakes. Limnology and Oceanography, 1977, 22(2) : 361-369.

[23] Editorial Board of Water and Wastewater Monitoring and Analysis Methods, Ministry of Environmental Protection of the People's Republic of China eds. Water and Wastewater Monitoring and Analysis Methods: 4th edition. Beijing: China Environmental Science Press, 2002. [国家环境保护总局《水和废水监测分析方法》编委会. 水和废水监测分析方法: 第 4 版. 北京: 中国环境科学出版社, 2002.] 
[24] Fang N, You QH, Liu LL et al. Evaluation of eutrophication in Poyang Lake wetland during autumn based on the cloud model. Acta Ecologica Sinica, 2019, 39(17): 6314-6321. [方娜, 游清徽, 刘玲玲等. 基于云模型的鄱阳湖秋季周边 湿地水体富营养化评价. 生态学报, 2019, 39(17) : 6314-6321.]

[25] Zhou YD, He BY, Kou JF et al. Inversion of lake trophic level index in Wuhan area based on GF-1 images. Resources and Environment in the Yangtze Basin, 2018, 27(6): 1307-1314. [周亚东, 何报寅, 寇杰锋等. 基于 GF-1 号遥感影像的 武汉市及周边湖泊综合营养状态指数反演. 长江流域资源与环境, 2018, 27(6)：1307-1314.]

[26] Hakanson L. An ecological risk index for aquatic pollution control-A sedimentological approach. Water Research, 1980, 14(8) : 975-1001. DOI: 10.1016/0043-1354(80)90143-8.

[27] Stoyneva M, Traykov I, Tosheva A et al. Comparison of ecological state/potential assessment of 19 Bulgarian water bodies based on macrophytes and phytoplankton (2011-2012). Biotechnology \& Biotechnological Equipment, 2015, 29( sup1) : S33-S38. DOI : 10.1080/13102818.2015.1047200.

[28] Li EH, Wang XL et al. Features of aquatic vegetation and the influence factors in Erhai lakeshore wetland. J Lake Sci, 2011, 23(5) : 738-746. DOI: 10.18307/2011.0511. [ 万恩华, 王学雷, 蔡晓斌等. 洱海湖滨带植被特征及其影响因 素分析. 湖泊科学, $2011,23(5): 738-746$.

[29] Galbraith-Kent SL, Handel SN. Lessons from an urban lakeshore restoration project in New York City. Ecological Restoration, 2007, 25(2) : 123-128. DOI: 10.3368/er.25.2.123.

[30] Jeppesen E, Jensen JP, Søndergaard M et al. Top-down control in freshwater lakes: The role of nutrient state, submerged macrophytes and water depth. Hydrobiologia, 1997, 342/343(0) : 151-164. DOI: 10.1023/A : 1017046130329.

[31] Zhang ZH, Yang SK, Han C et al. Effects of environmental stress on characteristics of low molecular weight organic acids secreted by macrophyte roots. J Lake Sci, 2020, 32(2) : 462-471. DOI: 10.18307/2020.0215. [张治宏, 杨诗卡, 韩超 等. 环境胁迫对水生植物根系分泌小分子量有机酸 (LMWOAs) 的影响特征. 湖泊科学, 2020, 32(2): 462-471.]

[32] Yao C, Hu XZ, Lu SY et al. Repression of nitrogen and phosphorus release from lakeshore sediment by five littoral-zone plants. Environmental Science, 2017, 38(2) : 589-599. DOI: 10.13227/j.hjkx.201604237. [姚程, 胡小贞, 卢少勇等. 几种水陆交错带植物对底质氮磷释放的抑制作用. 环境科学, 2017, 38(2): 589-599.]

[33] Xia CX, Yu D, Wang Z et al. Stoichiometry patterns of leaf carbon, nitrogen and phosphorous in aquatic macrophytes in Eastern China. Ecological Engineering, 2014, 70: 406-413. DOI: 10.1016/j.ecoleng.2014.06.018.

[34] Borin M, Salvato M. Effects of five macrophytes on nitrogen remediation and mass balance in wetland mesocosms. Ecological Engineering, 2012, 46: 34-42. DOI: 10.1016/j.ecoleng.2012.04.034.

[35] Wang YP, Zhu GW, Hong DL et al. Study on the thickness and environmental effects of sediment-water interface of phytoplankton and macrophyte dominated zones in Lake Taihu. China Environmental Science, 2013, 33(1) : 132-137.

[36] Dai YR, Wu J, Ma XH et al. Increasing phytoplankton-available phosphorus and inhibition of macrophyte on phytoplankton bloom. Science of the Total Environment, 2017, 579: 871-880. DOI: 10.1016/j.scitotenv.2016.11.002.

[37] Dondajewska R, Kozak A, Rosińska J et al. Water quality and phytoplankton structure changes under the influence of effective microorganisms (EM) and barley straw—Lake restoration case study. Science of the Total Environment, 2019, 660 : 1355-1366. DOI: 10.1016/j.scitotenv.2019.01.071.

[38] Freeman EC. Atmospheric change promotes increasing cyanobacteria dominance in Swedish lakes. Electronic Thesis and Dissertation Repository, 2018: 5516. 